\title{
La inconclusa edición crítica de las De situ orbis explanationes in Dionysium Afrum de Pedro Juan Núñez a través de la correspondencia de Gregorio Mayans y Francisco Cerdá
}

\author{
The Unfinished Critical Edition of Pedro Juan Núñez's \\ De Situ Orbis Explanationes in Dionysium Afrum through \\ the Correspondence of Gregorio Mayans \\ and Francisco Cerdá
}

\author{
Paulino Pandiella Gutiérrez \\ Universidad de Oviedo \\ pandiellapaulino@uniovi.es
} ORCID iD: http://orcid.org/0000-0001-7424-2916

\section{RESUMEN}

En este artículo mostramos el trabajo de Gregorio Mayans y Siscar y otros ilustrados valencianos en la recuperación de la obra de su compatriota el humanista Pedro Juan Núñez. Nos centramos en reconstruir el proyecto de edición de un texto de Núñez (De situ orbis explanationes in Dionysium Afrum) por Mayans y Francisco Cerdá Rico, tomando como fuente principal su correspondencia.

Palabras Clave: Núñez, Pedro Juan; Nunnesius, Petrus Ioannes; Mayans, Gregorio; epistolografía; crítica textual; humanismo; Ilustración.

\section{ABSTRACT}

In this article we show the task of Gregorio Mayans y Siscar and some other Valentian scholars from the XVIII century to retrieve the works of their countryman, the humanist Pedro Juan Núñez. We focus on reconstructing the edition project of a Núñez's text (De situ orbis explanationes in Dionysium Afrum) by Mayans and Francisco Cerdá Rico, using their collected letters as the main source.

Key words: Núñez, Pedro Juan; Mayans, Gregorio; Cerdá, Francisco; epistolography; Textual criticism; Humanism; Enlightenment. 


\section{VALORACIÓN Y PROYECTO DE EDICIÓN DE LA OBRA DE NÚÑEZ POR MAYANS}

La ingente correspondencia del ilustrado olivense Gregorio Mayans (16991781) nos ha permitido conocer la admiración que sentía por el trabajo de uno de los principales representantes valencianos del humanismo, Pedro Juan Núñez (circa 1525-1602). Esta afición, exacerbada por proceder ambos de la misma región, ha quedado testimoniada en innumerables elogios que ensalzan a Núñez como filósofo, como gramático y retórico, y como latinista y helenista. Muchos de estos encomios los ha recogido $\mathrm{H}$. Rausell, como la equiparación de su magisterio con el de Nebrija, la propuesta de su prosa latina como ideal del estilo, y su soberanía dentro de España en dialéctica, y conocimiento de la lengua griega ${ }^{1}$. Mayans consideraba también que Núñez era «blasón perpetuo de las buenas letras» (Mayans, 1984: 20), y que «en dos mil años no ha avido un hombre más exacto en el méthodo, ni más claro. Ha sido el Español que ha sabido mejor las dos lenguas Latina i Griega» (Mayans, 1986: 380).

El olivense canalizó su aprecio por la obra de Núñez en un proyecto de recuperación, edición y difusión de sus obras que, desgraciadamente, no pudo llevar a término. La edición de los humanistas españoles por Mayans ${ }^{2}$ ganó impulso sobre todo a raíz de su trato con una familia de impresores suizos, los Tournes $^{3}$ (Mayans, 1993: 21; Mestre, 2003: 321-322). Desafortunadamente, solo pudo completar la del Brocense, cuyos Opera omnia se publicaron en Ginebra en 1766. Para la de Luis Vives fue necesario que Juan Antonio Mayans rematase el trabajo de su hermano, ya fallecido, y lo diese a la imprenta de Benito Monfort en Valencia entre 1782 y 1790 (Mestre, 2003: 323-339). De otros humanistas publicó textos aislados. De Pedro Juan Núñez dio a la luz dos

${ }^{1}$ Rausell: «Los dos primeros maestros de España, Antonio de Lebrija i Pedro Juan Núñez» (2002: 131), «En el arte de enseñar la pureza del lenguaje (latino) [...] fue incomparable Pedro Juan Núñez. En la pureza del lenguaje ya conseguida i digna de ser propuesta como el ideal de estilo, fue admirable el mismo Núñez» (2002: 137), «Pedro Juan Núñez, que ha sido el que más ha sabido en España la lengua griega, sin exceptuar al comendador griego, i en método excedió a todos» (2002: 138), «Quien negará que explicó la dialéctica con agudeza inimitable Pedro Juan Núñez, [...] ninguno de esta escuela le ha excedido ni se ha igualado con él» (2002: 142).

2 Como dice Pérez i Durá (2010: 2484), en un artículo que ilustra bien el objetivo perseguido por Mayans con esta empresa, concebida ya en su juventud por influjo de su maestro el deán de Alicante Manuel Martí, «el ilustrado de Oliva había mostrado su interés y su deseo en que los hombres de letras españoles fuesen conocidos en Europa» y «se había esforzado en ello».

${ }^{3}$ La empresa fue una propuesta de don Gregorio a Samuel Tournes en su visita a Oliva en 1761, cuya buena acogida tuvo mucho que ver con la ya por entonces impresionante colección de manuscritos del ilustrado (para la relación entre Mayans y los Tournes, véase Mayans, 1993: 14-17, y especialmente su correspondencia, 600-626). 
discursos (Mayans, 1767) ${ }^{4}$ y una retórica que compartía volumen con otra de Nebrija, a la que añadió anotaciones propias (Mayans, 1774) y de la que diría: «tengo la Rhetórica de Núñez con exquisitas notas manuscritas. Este es el órgano que debe darse en todas las Universidades de España» (Mayans, 1998: 420), o «estoi haciendo imprimir una Rhetórica de singularidad i primor» (Mayans, 1989: 456-457) .

A pesar de que sus avances en ella fueran tan tenues, Mayans ya había concebido la empresa de la publicación de las obras de Núñez casi cuarenta años antes de fallecer, como dejó testimoniado a finales de 1742, cuando redactó la Acción de gracias a la Divina Sabiduría: «de buena gana comunicaré para que se publiquen por medio de la prensa muchas obras de los escritores más eruditos i sabios que ha tenido España, como [...] el maestro Pedro Juan Núñez» (Mayans, 1984: 602).

Son muchas las cartas, anteriores y posteriores a este extracto, en las que se manifiesta la búsqueda de obras de Núñez por Mayans, que en su constante intercambio de noticias librescas con sus corresponsales ya había llegado a decir: «en la librería de Marona se conservavan los manuscritos de Núñez. [...] Yo los pagaría a peso de plata» (Mayans, 1975: 343) ${ }^{6}$. En 1749, el hermano menor de Gregorio, Juan Antonio Mayans, que llegaría a alcanzar la dignidad de canónigo, trata el mismo tema con el inquisidor A. I. Orbe:

[...] No puede omitirse el comentario que Núñez hizo sobre Dionisio Afro, que es admirable, para moverle el gusto de su edición, que se hará con el favor de Dios. I aun con el tiempo hará mi hermano una Colección de todas sus obras, que no puede ser por ahora porque nos faltan algunas. Éste fue mucho mayor hombre que el Brocense i menos conocido. Si acaso a Vmd. le vinieren algunas obras

${ }^{4}$ El primer discurso, la Oratio de causis obscuritatis Aristoteleae, es uno de los trabajos más célebres de Pedro Juan Núñez, y había sido impreso con anterioridad al menos en cuatro ocasiones: 1554, 1591, 1667 y 1677 (Barbeito, 2000a: 351-353). Del segundo, compuesto para ser pronunciado ante Felipe III, esta era su editio princeps, y la única hasta la reciente edición crítica de Alarcos (2015).

5 Estas Institutiones Oratoriae de Núñez, cuya primera edición data de 1552 (Barbeito, 2000a: 338-340), ocupan la segunda parte del tomo, y van seguidas de unos esquemas o tabulae que Núñez imprimía aparte para que los estudiantes los manejaran con mayor comodidad (Barbeito, 2000b: 285-288). Lo que Mayans parecía no saber es que Núñez no había elaborado este esquema para las Institutiones Oratoriae, que todavía acusaban influencia ramista, sino para las Institutiones Rhetoricae de 1578 (Barbeito, 2000a: 344-347), que adoptaban los planteamientos de Hermógenes (edición crítica de ambos textos en Grau, 1994). La influencia de la doctrina retórica de Núñez en Mayans puede consultarse en Martínez (2004).

${ }_{6}^{6}$ Puede comprobarse el elevado número de trabajos de Pedro Juan Núñez que Mayans llegó a coleccionar en Mayans (1753: 79-88), catálogo de sus libros de autores españoles confeccionado por él mismo. 
suyas, no dege de comprarlas, que me parece aí no avrá ningún estimador de ellas (Mayans, 2007: 271).

La idea era editar los Opera omnia de Núñez, pero ese «comentario que [...] hizo sobre Dionisio Afro» demandó de Mayans especial atención, tanto por el valor intrínseco de la obra, como porque todavía estaba inédito entonces, como lo sigue estando ahora. Esta obra, transmitida bajo el título De situ orbis explanationes in Dionysium Afrum ${ }^{7}$, consiste en unos scholia de contenido diverso a la Periegesis de Prisciano, es decir, a una traducción en verso al latín del poema épico-didáctico griego de Dionisio Periegeta o Dionisio Afro, un compendio de geografía del mundo antiguo.

Ya hemos visto que a finales de 1742 Mayans manifestaba su intención de editar obras de Pedro Juan Núñez. En junio del año anterior ya había dicho: «Concluida esta impressión trataremos de la de Núñez, para que la República Literaria deva esto más a la Libreria Castelviniana ${ }^{8}$; i asseguro a V. Ex. que no ai autor antiguo tan felizmente ilustrado que Dionisio Afro por Núñez» (Mayans, 2006: 323). De nuevo en 1742 cita las De situ orbis explanationes in Dionysium Afrum como susceptibles de ser imprimidas con los fondos de la Academia Valenciana9 (Mayans, 1983: 317), y en 1757 dice «esto no quita que, si se ofreciere la ocasión de imprimir los comentarios a Núñez sobre Dionisio Afro, dejasse yo de publicarlos» (Mayans, 1998: 97). Aunque Mayans no habla antes de estas fechas de editar la obra, luego veremos que ya la conocía en $1736^{10}$. A ella se referiría en otro lugar como «el ingeniosíssimo i eruditíssimo comentario del nunca bastantemente alabado el maestro Pedro Juan Núñez» (Mayans, 1986: 10), y declararía que sus contenidos «ciertamente manifiestan una letura consumada en todos los antiguos geógrafos» (1986: 381). Dos años antes de su muerte, habiendo cedido la empresa de la edición de estas Expla-

7 Sobre este texto y su tradición manuscrita, Pandiella (2015).

${ }^{8}$ La impresión de la que habla es la de la por entonces inédita Censura de historias fabulosas de Nicolás Antonio, que se completó en noviembre de 1742 (para los detalles García Cuadrado, 2001). Respecto a la «Librería Castelviniana», más abajo veremos a qué se refería Mayans.

${ }^{9}$ Institución fundada en 1742 a instancias del propio Gregorio Mayans, concebida como una vía de obtención de financiación para editar las obras que contribuyesen a «recoger i ilustrar las Memorias Antiguas i Modernas, pertenecientes a España en todo género de Artes i Ciencias» (Mayans, 1983: 311).

${ }^{10}$ Supo de la existencia de esta obra en 1735, cuando a propósito de ella hizo a José Borrull la consulta que después trataremos. A juzgar por la ausencia de menciones anteriores al humanista en sus escritos, y por sus propias palabras en 1741: «estoi leyendo a Pedro Juan Núñez. Le conocí tarde» (Mayans, 1975: 343), las Explanationes fueron uno de los primeros textos de Núñez que manejó Mayans, aunque no el primero, pues en el índice de libros del olivense que fueron objeto de embargo en 1743 figuran unas «obritas de P. Juan Núñez copiadas de la R(ea)l Bib(lioteca) de mano propia» datadas en 1734 (Hoyos, 19551956: 257). 
nationes a su discípulo Francisco Cerdá Rico, todavía le diría sobre el mismo texto: «este librito (es) conveniente que se imprima aparte para que se esparza más i aya abundancia para fuera de España» (Mayans, 2000: 263).

En adelante, intentaremos reconstruir el inconcluso intento de Mayans de edición crítica de estas Explanationes de Núñez, y cómo Francisco Cerdá Rico lo sucedió en el empeño.

\section{REUNIÓN DE LOS EJEMPLARES (RECENSIO)}

La primera evidencia de que Mayans seguía la pista a las obras de Pedro Juan Núñez la tenemos en 1735. A sabiendas de que su antiguo maestro, José Borrull, servía en la Chancillería de Granada, Mayans le pide que visite la biblioteca del Colegio de San Pablo de la Compañía de Jesús ${ }^{11}$ y registre todos los textos manuscritos de Pedro Juan Núñez (Mayans, 1996: 170). Sin duda Gregorio, que trabajaba a la sazón en la Real Librería ${ }^{12}$, había hallado en su lectura de la Bibliotheca Hispana Nova de Nicolás Antonio la noticia de que las De situ orbis explanationes in Dionysium Afrum de Núñez se custodiaban en el centro jesuita ${ }^{13}$, y quiso ya por entonces asegurar que este trabajo quedase salvaguardado. En sucesivas cartas, Borrull da cuenta a Mayans de que esta es la única obra de Núñez allí guardada, la describe, y, después de que el olivense le pida un duplicado, lo mantiene al corriente del proceso de copia y del envío, que se prolongan más de un año (1996: 171-175). El ejemplar resultante, que Borrull envió a Mayans y que este recibió a finales de octubre de 1736 (1996: 174), no lo pedía el segundo para su propia colección, sino para la Real Librería (Mayans, 1972: 270 y 2000: 479; Mestre, 1970: 446) ${ }^{14}$, donde quedó

${ }^{11}$ Hoy, sede de la Facultad de Derecho de la Universidad de Granada.

${ }_{12}$ La actual Biblioteca Nacional de España, donde Mayans fue bibliotecario de 1733 a 1739.

13 «Quas ex codice collegii Jesuitarum Granatensis habuimus» (Antonio, 1788, II: 205206). Dirá Mayans en otro lugar: «el egemplar que D. Nicolás Antonio hizo mención que avía en Granada» (Mayans, 2000: 242).

${ }_{14}$ No conservamos la carta en la que Mayans hace la petición a Borrull, pero, a juzgar por las que le envía este a 1 y 22 de noviembre de 1735 (Mayans, 1996: 171-172), podemos datarla entre estas dos fechas. El encargo tiene pleno sentido, pues de la renta asignada a la Real Librería se preveía que una parte se destinase a la adquisición de obras de las que no hubiese ejemplares en el fondo de la institución (Novísima Recopilación, 1805, IV: 163). Siendo Mayans uno de los bibliotecarios ordinarios, no sabemos si para hacer efectivo el pedido solicitaría el permiso del bibliotecario mayor, por entonces Blas de Nasarre, o si sería este quien diese instrucciones a los bibliotecarios para la búsqueda de nuevos libros, dado que el titular de este cargo debía ser quien dirigiera la adquisición de nuevos volúmenes (García Ejarque, 1997: 47). 
guardado (Mayans, 1998: 340 y 2000: 242-243) ${ }^{15}$. Estos avatares los recoge J. P. Fuster, que dice haber leído de Juan Antonio Mayans: «hay en la Biblioteca del Rey otra copia [de las Explanationes de Núñez] que se sacó de la de Granada, valiéndose D. Gregorio Mayans para ello de D. José Borrull» (Fuster, 1827-1830, I: 195-196).

De vuelta en Oliva, adonde regresó en 1739, Mayans localizó otro ejemplar de la obra en una biblioteca privada, la de Juan Basilio Castelví16, quien acumuló los títulos de marqués de Villatorcas y conde de Cervellón, y pasó buena parte de su vida en el exilio en Viena por austracista, desde donde mantuvo correspondencia con Gregorio. No conservamos la epístola en que este informa a Castelví del hallazgo de las Explanationes en su biblioteca, pero sí la respuesta del aristócrata a 19 de abril de 1741: «Huélgome infinito que mi librería pueda servir de algo a sus útiles estudios de Vm. No sabía yo, o no me acordaba, que estuviesse en ella la Geographía de Núñez, ni creía que tuviéssemos otra cosa suya que una Topographía de España ${ }^{17} \gg$ (Mayans, 2006: 310). Más abajo veremos que en enero del mismo año ya estaba en posesión de una copia del manuscrito de Castelví, luego lo había encargado mucho antes de la composición de esta carta.

Pero el ejemplar de las Explanationes que envió Borrull a la Real Librería y este de Castelví, del que se aseguró una copia, no fueron los únicos que manejó Mayans, Veamos qué dice el olivense al agustino Enrique Flórez, primer autor de la España Sagrada, en 1746:

Pedro Juan Núñez en sus eruditísimos comentarios a Dionisio Afro, de los quales hice yo sacar una copia en el colegio de la Compañía de Jesús de Granada para la Biblioteca Real, además de la que yo tengo de la librería Castelvinia, cotejada por mí con otro ejemplar manuscrito (Mestre, 1970: 446).

El propio Gregorio cuenta en otro lugar cuál era ese segundo manuscrito: «El eruditíssimo comentario de Pedro Juan Núñez sobre Dionisio Afro, [...] que yo hice copiar en Valencia de un manuscrito que tenía el marqués de Villatorcas, i después le cotegé con otro manuscrito de D. Josef Salvador» (Mayans, 1998: 340). Juan Antonio Mayans corrobora esta información cuando, ya fallecido don Gregorio, dice a Francisco Cerdá Rico: «Vm. tiene la copia que

15 En agosto de 1779, Francisco Cerdá Rico confirma que ha visto el códice en la Real Librería (Mayans, 2000: 231).

16 Dicha biblioteca, sita en la llamada Casa Grande de la Plaza de Predicadores (actual Palacio de Cervelló), por entonces era probablemente la más nutrida y espléndida de Valencia, pues José de Castelví y Alagón, el padre de Juan Basilio, había reunido más de siete mil volúmenes (a decir de Ximeno, 1747-49, II: 190).

17 Castelví se equivoca al citar como de Pedro Juan Núñez una obra sobre topografía española (quizá se confundiese con la Hispania del flamenco Luis Núñez editada en Amberes en 1607). 
se sacó de la Castelviniana cotejada con otra de Josef Vicente del Olmo» (Mayans, 2000: 348) ${ }^{18}$. Más claro es el testimonio de V. Ximeno, a quien seguro informaron Gregorio o el mismo Juan Antonio:

Una copia de esta Obra [scil. las Explanationes de Núñez] [...] estava M.s. como dice D. Nicol. Anton. en la Librería de los PP. Jesuitas de Granada. En la Librería del Rey ay otra Copia, que hizo sacar D. Gregorio Mayans, y concuerda con una que ay en esta Ciudad en la Librería del Marqués de Villatorcas, de donde saco la suya D. Gregorio, el qual ha hecho un cotejo con otra que tiene Don Vicente Salvador, Secretario del Secreto de la Inquisición de Valencia (Ximeno, 1747-1749, I: 224) ${ }^{19}$.

En otra parte dice Ximeno a propósito de «Joseph Vicente del Olmo», nombre citado por Juan Antonio: «juntó en su Libreria muchos Mss. preciosos, de los quales conserva algunos su nieto D. Vicente Salvador y del Olmo, Secretario del mismo Tribunal» (1747-1749, II: 124). De esto se deduce que el códice de las Explanationes de Núñez con el que Mayans cotejó su copia pertenecía a Vicente Salvador del Olmo, que conservaba parte de la biblioteca que había pertenecido a su abuelo ${ }^{20}$.

En cuanto al momento en que Gregorio estuvo en poder de los dos ejemplares, podemos situarlo en enero de $1741^{21}$ o poco antes, puesto que el día 28 de este mes escribe: «estoi [...] cotejando la geografía de Núñez» (Mayans, 1975: 319). Téngase en cuenta, no obstante, que el olivense solo era propietario de una copia del manuscrito de Castelví; el de Del Olmo debió de manejarlo in situ o, en todo caso, se lo llevaría prestado.

\section{Cotejo de las Copias (COllatio)}

Si acabamos de ver que en enero de 1741 Mayans cotejaba los dos ejemplares citados, todavía en marzo seguía ocupado con esta colación, pues en una carta del día 11 cuenta que emplea el tiempo en «enmendar a ratos perdidos la

18 Más adelante veremos en qué circunstancias Cerdá recibió de Mayans este manuscrito en 1779, junto con una carta en la que el olivense explicaba detalles como «el [ejemplar] que embío se sacó de la librería del Conde de Cervelló» (Mayans, 2000: 242).

19 Sobre todos estos manuscritos, y sobre el resto de ejemplares de las Explanationes de Núñez, tanto los que se conservan como los ya desaparecidos, véase Pandiella (2015).

${ }^{20}$ El propio J. V. del Olmo nos da la prueba: «Sea de quien fuere [la traducción latina del poema de Dionisio Periegeta], la ilustró con eruditas notas nuestro Insigne Valenciano Pedro Iuan Núñez en el año 1573. Tengo las originales con mucha estimación: porque no se dieron a la Estampa» (Olmo, 1681: 3).

${ }^{21}$ Mismo año en que, como hemos dicho arriba, Gregorio Mayans declara por primera vez su intención de editar las De situ orbis explanationes in Dionysium Afrum de Pedro Juan Núñez. 
Geografía de Núñez» (1975: 346). El olivense trató el asunto con más gente, como indica que a 1 de febrero le escribiera su primo F. Pascual: «ese proyecto de la Geografía de Núñez fuera muy fácil de practicar si hubiese once como уо» (1975: 374n).

El 12 de febrero del mismo año, Gregorio revela que su hermano menor colaboraba con él en la empresa: «ahora cotejamos Juan Antonio i yo dos egemplares manuscritos de la Geografía de Núñez, obra exactíssima» (Mayans, 2005: 239). Esta noticia no se repite en otras cartas, más bien al contrario: ambos hermanos se refieren siempre a la colación de los testimonios como un trabajo de Gregorio, quedando poco claro en qué consistió la colaboración de Juan Antonio ${ }^{22}$.

En 1779, cuando Cerdá Rico pasa a hacerse cargo de la edición de las Explanationes de Núñez continuando el trabajo de Mayans, este le dice sobre el ejemplar que le va a hacer llegar: «en la copia se siguió primeramente un original después del cotejo con otros» (Mayans, 2000: 229). Dos semanas después, cuando hace efectivo el envío, dice del códice «[...] lo cotegé con el de Salvador i con el de Granada» (2000: 242). Sin embargo, hemos visto ya testimonios que mostraban que el único cotejo que Gregorio había hecho era el de su copia del manuscrito de Castelví con el de Del Olmo, y aún pueden ofrecerse más, como este de Juan Antonio a Cerdá sobre el ejemplar que su hermano había enviado al alicantino: «se sacó de la Castelviniana cotejada con otra de Josef Vicente del Olmo» (2000: 348) ${ }^{23}$.

Parece que Gregorio hizo creer a Cerdá que había cotejado todos los manuscritos para evitar el celo en las tareas críticas que este le demostraba, preguntándole acerca de los diversos ejemplares de la obra de los que había tenido noticia «para emendar a Núñez» (2000: 240-241). Era 1779 y habían pasado casi cuarenta años desde que el olivense concibiera la edición de las Explanationes de Núñez, sin haber llegado a culminarla. A dos años de su muerte, los síntomas de su vejez ya eran evidentes, y seguramente habría supuesto para él una satisfacción que uno de sus mejores discípulos aprovechase sus trabajos y lograse por fin publicar el texto. Pese a los desvelos de Cerdá, que era partida-

${ }^{22}$ Que Juan Antonio Mayans estudió las Explanationes de Núñez es un hecho constatado, pues confeccionó unas notas al texto, contenidas desde 1745 en el quinto de sus nueve volúmenes, casi todos inéditos, titulados Historia española (Alemany, 1994: 131-133) y localizados hoy en la Biblioteca del Real Colegio Seminario de Corpus Christi de Valencia con la referencia 302-309. El aprovechamiento que Juan Antonio hizo de estas notas se refleja en numerosas citas al texto de Núñez que presenta su Ilici (Mayans, 1771: 23, 55, $56,153,162,190,207)$.

${ }^{23}$ Al mismo destinatario decía unos meses antes Juan Antonio: «[...] los Comentarios de Pedro Juan Núñez a Dionisio Afro, que dictó a sus discípulos en Barcelona i en Valencia. De ambas escuelas vio i cotejó mi hermano egemplares, i aun del de Granada, que menciona D. Nicolás, hizo sacar una copia para la Bibliotheca Real, quando estava en ella» (Mayans, 2000: 479). No se menciona ningún cotejo con el ejemplar granadino ni con su copia. 
rio de colacionar todos los ejemplares, Mayans, quizá por apresurar la edición, le dirigió las siguientes palabras, falsas en parte, pero persuasivas:

Vi el Núñez de Salvador, i saqué todas sus varias lecciones, i el egemplar que D. Nicolás Antonio hizo mención que avía en Granada i quanto avía que ver. El que está en la Librería Real es copia del egemplar de Granada, que hizo hacer por mi medio Don Josef Borrull quando estava en aquella Chancillería. El que embío se sacó de la librería del Conde de Cervelló; después lo cotegé con el de Salvador i con el de Granada (2000: 242).

No obstante, aunque de esta manera terminó con las pesquisas de Cerdá sobre los manuscritos, no consiguió que se olvidase de otra cuestión bien próxima: la tradición indirecta del texto a través de dos historiadores contemporáneos de Pedro Juan Núñez, el catalán Jerónimo Pujades y el valenciano Gaspar Escolano, que al tratar sobre algunos topónimos citaron como autoridad a nuestro humanista ${ }^{24}$. Cerdá pretendía cotejar también estas citas con los manuscritos, y Mayans en un primer momento le había dicho: «las veces que Escolano i Pujades citan a Núñez (las) remitirá Juan Antonio» (2000: 243). Una semana después, el olivense ya le hacía saber que consideraba innecesario tal análisis de la tradición indirecta: «Las citas de Escolano i Pujades [...] piden algún trabajo más entretenido para cotejarlas con Núñez, lo qual por ahora no es menester, i creo que en adelante para nada servirá sino para el Prólogo» (2000: 246). Cerdá no se daba por vencido, y en su siguiente carta a Mayans dice: «Una vez que el Sr. Canónigo [scil. Juan Antonio Mayans] tiene apuntados los lugares de Escolano i Pujades, podrá excusarse mucho trabajo enviándome las páginas, que yo cotejaré las citas» (2000: 249). Pero la terquedad del olivense era aún mayor: «Los Comentarios de Núñez a Dionisio Afro, no necesitan de cotejos con las listas de Escolano i Pujades, ni de añadidura alguna $[\ldots] \gg(2000: 255)$.

Los últimos pasajes citados, además de demostrar el exceso de confianza, o bien la falta de rigor, de un Gregorio Mayans ya anciano, nos permiten concretar cuál debió de ser aquella colaboración de su hermano en la colación de las Explanationes: cotejar con el texto de los manuscritos las referencias al mismo que aparecían en las obras de Pujades y Escolano. Las conclusiones más notables que había extraído de ello se basaban en el hecho de que Escolano no

${ }^{24}$ Sobre las citas a Núñez de Pujades en su Coronica Vniversal del Principat de Cathalunya, y la utilidad de las mismas para conocer el manuscrito que empleó este autor, véase Pandiella (2015). Por su parte, Escolano recurre a Núñez en su Década primera de la historia de la insigne, y coronada ciudad y Reyno de Valencia, y en la segunda parte de esta obra, impresas respectivamente en 1610 y 1611 en Valencia por P. P. Mey (sobre las hipotéticas segunda y tercera décadas tenemos una noticia del catálogo manuscrito de Ingenios Valencianos de Onofre Esquerdo, véase Ximeno [1747-1749, I: 282], según la cual los dos tomos estaban ya terminados, pero se perdieron). 
mencionaba una obra concreta al citar a Núñez. Juan Antonio trató de contrastar lo que este historiador atribuía al humanista repasando tanto las De situ orbis explanationes in Dionysium Afrum como la carta que Núñez envió a Schott tratando sobre la obra de Pomponio $\mathrm{Mela}^{25}$, sus dos únicos escritos de tema geográfico conocidos. Sin embargo, según hizo constar en su Ilici, el Mayans menor no halló el origen de esas pretendidas citas (Mayans, 1771: 55$56,190)^{26}$. Cerdá pudo saber esto directamente de uno de los dos olivenses, o bien a través de Ximeno, que se había hecho eco de ello: «Gaspar Escolano cita esta excelente Obra [las Explanationes de Núñez] varias vezes; pero se ha observado, que el exemplar que él vio, tenía cosas que no se hallan en estos» (Ximeno, 1747-1749, I: 224).

No sabemos mucho más de la colación a que Mayans sometió las De situ orbis explanationes in Dionysium Afrum. Desde luego, que la consideraba necesaria es obvio: «los dos egemplares que he visto están mui viciados y necessitan de cotejo» (Mayans, 1998: 97), decía en 1757. En esa fecha en realidad eran tres los ejemplares que había visto, y ya en 1741 había cotejado dos de ellos, su copia del manuscrito de Castelví y el ejemplar de Del Olmo, con el que no pudo quedarse. Sobre las páginas del códice que le pertenecía apuntó las divergencias textuales que con respecto a este presentaba el otro. Lo sabemos porque, al recibir Cerdá en 1779 el ejemplar de Mayans, le dijo: «lo que está añadido de mano de Vm. son emiendas necesarias a la obra, y parte se conoce que las haría el mismo Núñez para mejorar sus comentarios» (Mayans, 2000: 275); a lo que Gregorio le respondió: «lo que de mi letra está añadido, no es mío, sino del original de Olmo» (2000: 277). Una vez colacionados los dos testimonios, Mayans interrumpió el trabajo, «i quedó después por hacer la diligencia crítica de escoger la letura mejor» (2000: 229).

\section{BÚSQUEDA DE FINANCIACIÓN}

La principal razón de que Mayans no llegase a editar las Explanationes fue crematística. Nos consta que el olivense recurrió a las más elevadas figuras de la política española para que financiasen sus trabajos filológicos, como ejemplifica el siguiente extracto de una carta enviada en febrero 1766 a Manuel Roda y Arrieta, Secretario de Gracia y Justicia de Carlos III: «Quisiera tener

${ }^{25}$ Publicada en Mela (1748). Se conserva el original en el manuscrito VLQ 120 de la Biblioteca de la Universidad de Leiden.

${ }^{26}$ Juan Antonio sugiere que Escolano quizá manejase un ejemplar distinto de las Explanationes desconocido por él, o incluso que hubiese hecho un uso fraudulento del prestigio de Núñez como aval de sus ideas propias. Aunque las dos opciones son posibles, puede proponerse una tercera: que Escolano, contemporáneo y conciudadano de Núñez, se refiriese al citarlo a su testimonio oral. 
la dicha de que V.S. Ilma. se declarasse patrón mío, para publicar una increíble muchedumbre de obras [...]; porque buen nombre i fama V.S. Ilma. sabe mui bien que no me faltan, pero para el puchero nada sirven» (Mayans, 1990: 203). Mayans debió de obtener una respuesta positiva, pues una semana después escribía a Roda otra epístola en la que enumeraba más de veinte trabajos, obras propias y ediciones de obras ajenas, que ya tenía preparados, entre ellos: «Deseo imprimir el Dionisio Afro, De situ orbis, con un eruditíssimo comentario del incomparable maestro Pedro Juan Núñez, para que en las univers(id)ades se aprendan los elementos de la geografía» (Mayans, 1990: 207). De este listado de obras, Gregorio no llegó a ver publicados más que cinco trabajos suyos y dos reediciones de otros textos (1990: 40). Por eso no extraña que en julio del mismo 1766 dijera «dedicaré al Exmo. conde de Aranda, nuestro patrón, el eruditíssimo comentario de Pedro Juan Núñez sobre Dionisio Afro» (Mayans, 1998: 340), significando probablemente que buscaba financiación para el mismo texto en otros estadistas.

Manuel Roda fue también quien encargó a Mayans por las mismas fechas la elaboración de un plan de estudios universitario, que en 1767 ya estaba listo. En él, el olivense incluyó algunas obras de Pedro Juan Núñez como libros de texto para el estudio de la gramática, de la retórica y de la lengua griega (Peset y Peset, 1975: 197, 210, 212), pero lo que nos resulta especialmente significativo es que para el estudio de la poética propusiera el poema épico-didáctico de Dionisio Periegeta ${ }^{27}$, apostillando «que publicaré con las eruditísimas notas de Pedro Juan Núñez» (1975: 219).

Por desgracia, los esfuerzos emprendidos por Mayans para encontrar quien se ofreciera a financiar la publicación de las Explanationes fueron vanos. Ni siquiera tuvo éxito al sugerir la empresa en 1768 a un erudito y promotor de los estudios clásicos como Pedro Rodríguez de Campomanes (Mayans, 1997: 460), que en aquel momento, además de ocupar una poderosa posición como Fiscal del Consejo de Castilla, presidía instituciones tan importantes para la promoción de la cultura como la Real Academia de la Historia y la Compañía de Impresores y Libreros ${ }^{28}$. De ello daría cuenta mucho después a Cerdá: «[...]

27 Mayans había sabido por el embajador inglés Louis de Visme, durante la visita de este a Oliva en 1764, que en las escuelas británicas se utilizaba esta obra para enseñar geografía a los estudiantes (Peset, 1975: 173). Aunque no llegó a publicar las Explanationes, sí lo hizo con esta versión latina del poema de Dionisio, incluida en Mayans (1768), una colección de textos latinos antiguos; cada una de las partes que componen esta obra incorpora su propia portada, como si se tratase de un tomo exento, y en una de ellas, «Mela sive liber de Geographia» (1768: 125-200), el texto que ocupa el primer lugar es la traducción latina por Prisciano de la Periegesis de Dionisio (1768: 127-156).

28 Sobre el mecenazgo literario de Campomanes, sus vastos conocimientos de las lenguas clásicas y de la historia, y sobre cómo trató de promover y proteger estos estudios desde su puesto en el gobierno de Carlos III, véase Gil Fernández (1976). 
no lo he egecutado porque no avia quien quisiesse costear la impresión» (Mayans, 2000: 229).

\section{El relevo de Mayans: Francisco Cerdá Rico}

Mayans, desde que terminara la colación de los manuscritos en 1741, había dejado congelado el proyecto de edición de las Explanationes de Núñez, y tampoco su fracaso en la búsqueda de fuentes de financiación para la impresión le daba ánimos para continuarlo. En este estancamiento se hallaba la empresa cuando Francisco Cerdá Rico (1739-1800) pasó a hacerse cargo de ella en 1779, como hemos anticipado. Cerdá, discípulo y protegido de Mayans que gracias a las influencias de este ya ocupaba un puesto de escribiente en la Real Biblioteca en enero de 1766, mantuvo con Gregorio una asidua correspondencia, centrada a menudo en temas literarios y editoriales ${ }^{29}$. A raíz de la publicación por Mayans de los Opera omnia de El Brocense para la que había prestado su ayuda, es precisamente en el verano de 1766 cuando Cerdá concibe un proyecto de edición de obras de humanistas españoles con Pedro Juan Núñez a la cabeza $^{30}$, y busca la colaboración del olivense:

Yo tuve la fortuna de lograr el primer juego del Brocense, [...] embiado por los Tournes con la expressión de embiarse «por mandado de Dn. Gregorio Mayans». [...] Ojalá sirva de estímulo para que otros se animen a reimprimir las obras de los demás españoles eruditos. Bien quisiera que se hiciesse esto con las de Núñez (Mayans, 2000: 170).

He animado a Dn. Manuel Monfort, que se halla en esta Corte, a que tome por su cuenta reimprimir algunas obritas de nuestros españoles, ya casi sepultadas en el olvido por falta de egemplares [...]. Yo quisiera que comenzássemos por Núñez; pero no sólo carezco de casi todas sus obras, sino que ni aun las he visto venales en esta Corte. [...] El fomento de Vm. podría solo hacer que viéramos salir a nueva luz los Núñez con lo manuscrito [...] (2000: 169).

En 1767, Cerdá busca el consejo de Mayans sobre «las obras que Vm. juzgasse que merecían reimprimirse» (2000: 178), refiriéndose entre otras a las de Núñez. Dos años después tantea a Gregorio sobre la edición de los textos del humanista, pues sabía que era uno de los proyectos del olivense (2000: 186). No se nos ha conservado su respuesta, pero parece que Mayans consintió en que Cerdá se dedicase a editar a Núñez, al estar él ocupado en la impresión

\footnotetext{
${ }^{29}$ Acerca del influjo de Mayans sobre Cerdá, y de su relación y sus aficiones comunes, especialmente el humanismo español del XVI, nos remitimos a Mestre (1970: 338-355) y Mayans (2000: 7-74).

${ }^{30}$ No en vano diría Cerdá: «Será razón que cuidemos de dar a conocer primero a nuestros valencianos» (Mayans, 2000: 227).
} 
de trabajos propios. El alicantino le solicita entonces las obras del humanista que había ido reuniendo ${ }^{31}$, dado que la Real Librería carecía de casi todas ellas, y hace esta petición en nombre del bibliotecario mayor, Juan de Santander, quien también escribe en la misma carta (2000: 187-188). Parecía que tomaba forma al fin el proyecto de edición de las obras completas de Pedro Juan Núñez: «Supuesto que Vm. [...] me permite dar a luz las de nuestro paisano Núñez, he determinado recogerlas i ordenarlas todas» (2000: 187-188) ${ }^{32}$. Sin embargo, sabemos que la respuesta de Mayans fue negativa por su hermano Juan Antonio:

Recién publicada la Colección de las obras del Brocense, embió D. Juan de Santander a decir a mi hermano que le remitiesse los libros, impressos i manuscritos, de Pedro Juan Núñez para hacer una impressión de ellos, por cuenta de la Bibliotheca Real. La respuesta fue que essa era buena idea para un librero, que la $\mathrm{Bi}$ bliotheca del rei devía imprimir lo que ninguno podía egecutar en el mundo (2000: 110-111).

Un argumento de esta inconsistencia solo puede entenderse como el pretexto de Gregorio para no ceder el fruto del trabajo propio a otros que usurpasen así sus méritos. Seguramente, todavía confiaba en conseguir financiación para editar él mismo a Núñez. También su amigo el bibliotecario real $\mathrm{M}$. Martínez Pingarrón da testimonio de esta negativa de Mayans y de la insistencia de Cerdá el 8 de agosto de 1769:

Ya resolló Cerdá. Me ha dicho que recibió respuesta de Vmd., a quien ha vuelto a escrivir el bibliothecario mayor, i que el asunto es pedir a Vmd. unas obras de Núñez, que Vmd. dice no puede embiarles porque necesita tenerlas a la mano. Que dice a Vmd. haga le copien no sé qué de ellas. Dígele que Vmd. no tenía amanuense para sí, i cerró con que, aviéndose de pagar por aquí, podía Vmd. hacerlas copiar a qualquier estudiante (Mayans, 1989: 210-211).

No sería hasta pasados diez años cuando Mayans y Cerdá volvieran a tratar de Pedro Juan Núñez en su correspondencia, casi limitándose a nuestras De situ orbis explanationes in Dionysium Afrum. Conocedor de la estima que Gregorio tenía por este texto, el alicantino se proponía incluirlo en una colec-

31 En Mayans (1753: 79-88) figuran las que adquirió antes de 1753, entre ellas las De situ orbis explanationes in Dionysium Afrum, que califica como «eruditissimae, \& luce publica dignissimae» (1753: 87).

32 Las obras de Núñez que por entonces estaban en manos de Cerdá se enumeran en Rausell (2002: 151n), aunque el alicantino acabaría haciéndose con más: la copia de las De situ orbis explanationes in Dionysium Afrum que como luego veremos le envió Mayans, las que él mismo encontró (Mayans, 2000: 339), y las halladas por José Vega Sentmenat en Barcelona (descritas en la correspondencia entre este y J. A. Mayans, como se estudia en Fuente, 2012). 
ción de obras raras de autores españoles que titularía Clarorum Hispanorum Opuscula selecta et rariora tum Latina tum Hispana ${ }^{33}$ : "Yo creo que este es el mejor medio de dar a conocer el mérito de muchos ingenios desconocidos, $\mathrm{i}$ de imprimir obritas que de otra suerte nunca salieran a luz, o no se reimprimieran por cortas, o desconocidas» (Mayans, 2000: 231). La implicación del alicantino en este trabajo mereció que Mayans lo llamara «restaurador de las letras de España» (2000: 246). De las Explanationes de Núñez puede decirse que nunca estuvieron tan cerca de publicarse como durante la preparación de esta selección de obras, pues Mayans puso sus materiales y su trabajo en el texto a disposición del alicantino: «Toda su vida tuvo ganas de publicar esta obra, i la encomendó a Cerdá, a lo último de ella» (2000: 472), diría de él su hermano Juan Antonio en 1784.

Aunque por desgracia solo el primer volumen de estos Opuscula llegó a publicarse, la correspondencia del alicantino testimonia los planes que tenía para la colección, y cómo constantemente consultaba al mismo Mayans, y tras fallecer este a su hermano, acerca de la conveniencia de incluir una u otra obra, o de si podrían proporcionarle tal o cual texto. En carta a Gregorio decía Cerdá del primer tomo: «Si la obra se vende se continuará», y aseguraba que en el segundo volumen habría algo de Pedro Juan Núñez. Repetidas veces tratan los dos eruditos de qué se incluiría en estos segundos Opuscula, manteniendo siempre las De situ orbis explanationes in Dionysium Afrum de Núñez (2000: 227, 231-233, 240): «Me acuerdo que vi el Dionysio Afro que conserva Vm. i siempre he tenido deseo de que se publiquen sus comentarios que quiero sean el adorno del tomo 2» (2000: 231). Tanto entusiasmo sentía por esta obra, que quería que figurase la primera del segundo tomo, que estaba dispuesto a retrasar por ella la impresión de los Opuscula con tal de que figurase entre ellos (2000: 243). El olivense lo apoyaba: «el Núñez sobre Dionisio es obra que deve imprimirse por sí» (2000: 247).

${ }^{33}$ El proyecto de estos Opuscula, tema frecuente en la correspondencia de Cerdá, se trata brevemente en Mayans (2000: 31-33 y 1996: 190-193), pero sobre todo en Mestre (2000). Cerdá da a conocer la idea a Mayans en carta del 27 de julio de 1779 (Mayans, 2000: 223), consultándole incluso la conveniencia del título y anunciándole que para el segundo tomo se publicaría, entre otros humanistas españoles, a Pedro Juan Núñez, y Mayans da su visto bueno y ofrece su colaboración (Mayans, 2000: 225). En realidad, Cerdá había concebido la empresa mucho antes, como dice en una carta del 10 de agosto de 1779 : «Lo que más siento es haver perdido 10 años o 12 desde que pensé dar esta colección hasta ahora. Quando entré en la Real Bibliotheca se lo propuse a Santander. Empezó i se enfrió» (Mayans, 2000: 231). El título Opuscula no sería óbice para incluir textos extensos, ni sería un problema no ofrecer las obras en orden cronológico, ni de materia, ni de autor, ni siquiera en distribuir las de un mismo autor en distintos tomos (Mayans, 2000: 243-244); esto decía Cerdá que lo justificaría en el prólogo, y así lo hizo (Cerdá, 1781: xi-xii). 


\section{PRIMER PROYECTO DE PUBLICACIÓN DE LAS EXPLANATIONES POR CERDÁ}

Mayans asesoraba y ofrecía sus conocimientos a Cerdá sobre los textos a editar ${ }^{34}$, pero su papel en los Opuscula iba más allá. Sobre todo, el alicantino recurría a él para que le enviase los raros ejemplares de muchas obras que querían editar o reeditar, muy difíciles de encontrar fuera de la colección de Gregorio: «Doy a Vm. muchíssimas gracias por la generosidad con que contribuye a franquearme preciosíssimos monumentos para mi colección» (2000: $275)^{35}$.

Después de que Cerdá pidiese a Mayans las Explanationes de Núñez entre otras obras que pensaba incluir en el segundo tomo de los Opuscula (2000: 275), se aprecia en la respuesta que el olivense se muestra un tanto receloso, y de hecho hace ver a Cerdá que le mandará el manuscrito bajo ciertas condiciones: le exige una considerable labor de crítica textual, que más adelante analizaremos, antes de publicar el texto (2000: 237). El alicantino se compromete a acatar sus directrices, e incluso hace al respecto algunas observaciones que van más allá de lo que Mayans había pensado (2000: 240). Esto debió de satisfacer a Gregorio, pues en su siguiente carta, tratando de los ejemplares de la obra que conoce, dice «el que embío se sacó de la librería del Conde de Cervelló» (2000: 242) ${ }^{36}$. Sin embargo, no había realizado tal envío, pues más tarde Cerdá le sugiere con sutileza: «No he presentado al Consejo los opúsculos para el tomo $2 .^{\circ}$ ni pedido censor fijo, porque quiero que salga en él lo de Núñez a Dionysio» (2000: 253) ${ }^{37}$. Al no obtener la reacción esperada, la siguiente petición es mucho más directa: «Ya que no resta más que sacar una buena copia de los Comentarios de Núñez, puede Vm. servirse dirigirlos a

${ }^{34}$ Tanto valoraba Cerdá su opinión que incluso se excusó con él por no haberle consultado qué obras incluir en el primer tomo de Opuscula, pretextando que había seleccionado algunas para las que previamente tenía licencia de impresión, y que el proceso se vio acelerado por las prisas del editor, Antonio de Sancha (Mayans, 2000: 240), colaborador habitual de Cerdá y también conocido de los Mayans, a quienes había recurrido en 1776 para perfeccionar su edición a Lope de Vega (Mayans, 1993: 10, y sobre todo la correspondencia entre ellos, 549-596).

${ }_{35}$ Mayans enviaba los paquetes postales al intelectual y político Eugenio Llaguno y Amírola, según le había dicho Cerdá, para que se los hiciera llegar: «[...] Cualquier cosa que se necessite remitir, se puede dirigir sucessivamente por el correo a Dn. Eugenio Llaguno i Amírola, Oficial de la $1 .{ }^{a}$ Secretaría de Estado $=$ Sn. Ildefonso, que se lo remitirá a Sancha o a mí» (Mayans, 2000: 233). En otra ocasión Sancha había dado las mismas instrucciones a Mayans (Mayans, 1993: 559; sobre la relación profesional que unía a Mayans, Cerdá, Sancha y Llaguno, puede consultarse Mestre, 1970: 338-355, especialmente 349352).

36 Recordemos que Mayans disuadió a Cerdá de colacionar otros testimonios.

37 El Consejo al que se refiere Cerdá es el Consejo de Castilla, al que había que solicitar licencia de impresión según lo dispuesto por la monarquía borbónica en 1705 (Bragado y Caro, 2004). 
Llaguno, que sólo por ellos tengo detenida la presentación de muchos libritos que formarán el 2. ${ }^{\circ}$ tomo» (2000: 257). Continúan las trabas de Mayans, que pide a Cerdá le confirme «que tendrá un mes desocupado» para trabajar en el texto (2000: 259), y las garantías del alicantino de que todo se hará siguiendo su método (2000: 261). Finalmente, transcurridos casi cuatro meses desde la petición original de la obra a día 10 de agosto de 1779, Cerdá confirma que la ha recibido en su carta a Gregorio del 7 de diciembre: «El Sr. Llaguno me entregó las Prelecciones de Pedro Juan Núñez a Dionisio Afro, juntamente con la obrita de éste [...], que es quanto podía desear para hacer yo la mía en los Opúsculos con presencia de todo» (2000: 275). El alicantino no esperó más para empezar la edición de la obra, sino que en esta misma carta dice haberse puesto a ello.

Las últimas ocasiones en que Mayans y Cerdá tratan de las Explanationes de Núñez datan de agosto de 1781, y las noticias no eran buenas. Cerdá anuncia la conclusión del primer tomo de Opuscula para el mes siguiente, y declara que el segundo volumen constaría, por completo o en su mayoría, de obras inéditas sacadas de la biblioteca privada de Manuel Roda (2000: 320) ${ }^{38}$. Además, hace alusión ya a un tercer tomo: «Empezará por las Notas de Núñez a Dionysio Afro i quiero que todo sea ex Bibliotheca Mayansiana». Mayans ve así pospuesta la publicación de las Explanationes:

La librería del Exmo. Sr. D. Manuel de Roda podrá emplear el exquisito gusto de $\mathrm{Vm}$. en escoger muchas obras mui eruditas. Quando llegue su turno a las explanaciones de Dionisio Afro de Núñez, procuraremos que no les falte buena compañía, sacada de la Bibliotheca Mayansiana (2000: 317) ${ }^{39}$.

Gregorio fallecería en diciembre de ese año 1781, sin haber visto satisfecho su deseo de que esta obra de Pedro Juan Núñez se publicase.

\section{Segundo proyecto de publicación de las Explanationes POR Cerdá}

La edición del segundo tomo de los Opuscula quedaría suspensa hasta que Cerdá la retomase en 1784, como dice a Juan Antonio Mayans en marzo de dicho año: «Se continúa la colección de Opúsculos bajo los auspicios del Sr.

38 Ya se había referido a manuscritos que había tomado de la biblioteca de Roda (Mayans, 2000: 300), y hace de él menciones honoríficas en el único volumen de Opuscula publicado (Cerdá, 1781: viii, xiii y xv).

39 Esta carta figura como del 15 de agosto de 1780, pero en realidad es un año posterior. En el encabezamiento dice Mayans «Vm. me ha regocijado con su carta llenísima de muchas i agradables noticias. Iré hablando de ellas según el orden con que Vm. las refiere». No hay más que comparar el contenido con el de la de Cerdá del 11 de agosto de 1781 (Mayans, 2000: 320-321) para constatar que la primera es la respuesta a la segunda. 
Conde de Floridablanca» (2000: 339) ${ }^{40}$. Tuviera que ver con la muerte de su benefactor Manuel Roda en 1782, o con el fracaso editorial del primer volumen, el hecho es que los obstáculos para continuar la colección habían sido económicos, pero ahora el alicantino se había ganado un poderoso patrocinador.

Juan Antonio Mayans había apuntado, en el margen de una carta de diciembre de 1781 que Cerdá le escribía condoleciéndose por el fallecimiento de Gregorio: «Los libros de la librería mayansiana que tiene D. Francisco Cerdá son: [...] Núñez sobre Dionisio ms» (2000: 325). Por tanto, no debió de extrañarle que el alicantino, en la misma carta en que le notificaba haber dado con ciertos escritos de Núñez le comentase sobre los Opuscula: «Tengo tentación de poner en este 2. ${ }^{\circ}$ tomo los Comentarios de Núñez a Dionisio Afro» (2000: 339). De ello le da el visto bueno Juan Antonio, recomendándole también añadir «algo de lo nuevamente hallado, que es precioso sobre manera» (2000: 341). Queda así abierto un diálogo entre ambos eruditos sobre las obras susceptibles de figurar en la colección de Opuscula, en el que se registran determinados hallazgos de trabajos de Pedro Juan Núñez ${ }^{41}$, y también peticiones por Cerdá a Juan Antonio tanto de asesoramiento como de libros.

Tras consultar con el Mayans menor qué textos incluir en el segundo tomo, el alicantino dispone presentar el listado a Floridablanca: «Creo que el Sr. Conde apruebe pongamos lo más de Núñez en el 2..$^{\circ}$ tomo». Incluso anticipa, con mucho optimismo, publicar obras de Gregorio Mayans en la tercera entrega de los Opuscula (2000: 341). En sus respuestas, Juan Antonio da cuenta pormenorizada del hallazgo de obras de Núñez en la biblioteca del Colegio de los Carmelitas Descalzos de Barcelona (2000: 342-344) que por otro lado le comunicaba José Vega Sentmenat (Fuente, 2012). Cerdá recibe la noticia con entusiasmo, y recupera la idea de publicar las obras completas del humanista: «yo tendría disposición aquí de imprimirlas todas» (Mayans, 2000: 344). El conde de Floridablanca daba pábulo a este optimismo:

Ahora digo a Vm. que está ya allanado todo, i el Sr. conde de Floridablanca, quem aget penna metuente solvi / fama superstes ${ }^{42}$, sufraga los gastos, et aliquid amplius. No hai más detención que la de no estar concluida la fundición. Como

${ }^{40}$ La obtención de esta financiación por parte de Cerdá, desde su cargo de Oficial de la Secretaría de Estado de Indias, se comenta en Alemany (1994: 331-332).

${ }^{41}$ Uno de ellos es el que describe Cerdá en esta carta de 2 de marzo de 1784 a J. A. Mayans (Mayans, 2000: 338-339), y el otro el de José Vega Sentmenat, político y aristócrata catalán a la sazón presidente de la Academia de la Historia de Barcelona, anunciado al mismo Juan Antonio el 16 de marzo de 1784 y más concretado en la carta a este del 20 del mismo mes (Mayans, 2000: 480 y 483 respectivamente). Estos descubrimientos de obras manuscritas de Núñez propiciarían un triángulo epistolar entre los tres estudiosos implicados (estudiado en Fuente, 2012, y otros avatares de los mismos códices en Núñez, 2011).

42 Hor., Carm, 2, 2, 7-8; Cerdá adapta el original a la sintaxis de su texto, sustituyendo el demostrativo illum por el relativo quem. 
presenté a S.E., no sólo el plan del tomo II, sino también una larga lista de opúsculos, i noté en ella que podría hacer colección separada de los de Morcillo, Núñez, etc., le pareció mui bien; con este motivo hablamos de lo inédito de Núñez i quiso la nota para pedirlo por Real Orden; lo suspendí por ver si Vm. me contestava (2000: 347).

Juan Antonio se muestra satisfecho al ver vencidos los problemas que habían impedido a su hermano editar a Pedro Juan Núñez: «El Sr. Conde de Floridablanca con su buen gusto vence la dificultad que avía en llevar adelante la empressa por la falta de despacho. Mientras no vayan en consonancia la erudición i el bolsillo mercantil no estamos bien [...]» (2000: 347).

De esta carta del 3 de julio de 1784 en adelante tenemos escasa información sobre los avatares de la empresa. Lo seguro es que no se publicó ningún otro tomo de los Opuscula, con o sin textos de Pedro Juan Núñez. Las obras del humanista halladas por Vega Sentmenat fueron remitidas a Madrid para su edición (Fuente, 2012: 19-21) ${ }^{43}$, y, aunque más tarde regresaron a Barcelona (Núñez, 2011: 257) ${ }^{44}$, hicieron el viaje en balde. Sentmenat no podía evitar sentirse nervioso al haber sido él el responsable de su partida, dado el celo con que los Carmelitas velaban por su patrimonio. En enero de 1786 decía al Mayans menor:

Deseo saber del laboriosíssimo Cerdá, ¿en qué se ocupa? Ya Vm. sabrá que se llevaron de la Bibliotheca de los Descalços los tomos manuscritos del P. J. N. de que di aviso a Vm. por cuyo medio huvo la nota. Dessearía mucho que no se descuidassen a su tiempo de restituirles para que se saque a los frailes de su preocupación por la que me miran como un espión de sus cosas (Mayans, 2000: $513)$.

Mediado 1789, aún no había recibido noticias de los avances de Cerdá: «¿Querrá Vm. creer que de Madrid aún no han restituido los 2 tomos manuscritos de Pedro Juan Núñez [...], ni sé que adelanten la edición anunciada?» (2000: 559). Tampoco tenía buenas referencias del alicantino, pues no solo Juan Antonio le había reconocido «Cerdá es tardón» (2000: 487), sino que él mismo confesaba al canónigo: «Me decía el Fiscal del Crimen, que le conoce, que él [scil. Cerdá] es raro también en el régimen de vida. Desconfiaba que llegasse

${ }^{43}$ En principio se iba a encargar una copia, pero Cerdá supo mover hilos para lograr que se enviaran los códices. De la poca colaboración de los Carmelitas da muestras Sentmenat a Juan Antonio en repetidas ocasiones, por ejemplo: «No hai que pensar en que voluntariamente embíen los tomos. [...] Piensan que [...] perdería el manuscrito i desconfían de todo. Si les viene orden del rei, sospecharán de mí. Quiçá lo ocultarán, i por esto no les aviso antes, porque de fixo nos burlarían» (Mayans, 2000: 486).

${ }^{44}$ Solo podemos fijar un terminus ante quem de este hecho, 1824, año de la publicación del tomo XVIII de la obra de Villanueva, que da cuenta del traslado de los códices y de su regreso (Villanueva, 1803-1852, XVIII: 213). 
a continuar lo prometido, que es mucho, i sabe quántas otras ocupaciones le distraen» (2000: 480). En efecto, parece que las ocupaciones burocráticas de Cerdá le dejaban cada vez menos espacio para las literarias ${ }^{45}$.

De este modo fracasó una empresa dilatada durante medio siglo, el proyecto de edición de las De situ orbis explanationes in Dionysium Afrum de Pedro Juan Núñez en primer lugar, y después de todas las obras del humanista, concebido por Gregorio Mayans y practicado por él mismo, por su hermano y por su discípulo Francisco Cerdá Rico. A pesar de que estos eruditos llegaron a reunir un elevado número de textos de Núñez, tarea entonces realmente ardua, las circunstancias impidieron que la imprenta los difundiera, condenando a su autor a un desconocimiento del que todavía no ha sido suficientemente resca$\operatorname{tado}^{46}$.

\section{TÉCNiCAS de CRÍtica teXtual empleadas POR Mayans y Cerdá}

Hemos visto que Mayans completó la collatio de dos manuscritos de las Explanationes de Núñez y detuvo ahí su trabajo. Cuando casi cuarenta años despues cedió el proyecto a Cerdá, ya adelantamos que le exigía un mes para completar lo que él había empezado, y de hecho no dejó de indicarle a través de sus cartas las tareas ecdóticas que debía acometer, entre ellas cómo proceder en la examinatio, en la selección de variantes para llegar a una adecuada fijación del texto (constitutio textus). Por el interés que esta parte de su corresponden$\operatorname{cia}^{47}$ tiene para la historia de la crítica textual en España, vamos a hacer una resumida exposición de su contenido.

Empecemos por recordar la falta de rigor, hoy imperdonable, que Mayans cometía al prevenir a Cerdá de cotejar todos los testimonios conocidos. Gregorio le había enviado un único códice, que incorporaba el texto de un manuscrito con anotaciones de las lecturas divergentes de otro, pero sabía que había al menos otro ejemplar que no era copia de ninguno conservado y que él no había colacionado, aquel del que Borrull le hizo llegar un apógrafo desde Granada. Quizá menos grave es que descartase el cotejo del texto de Núñez con las citas de Pujades y Escolano, si realmente su hermano o él mismo se habían

45 A pesar de que alargó su vida trece años desde entonces, el último libro que el alicantino publicó fue la Crónica de Don Alfonso el Onceno en 1787, también en la imprenta madrileña de Antonio de Sancha.

46 A la luz de los estudios de la vida y obra de Pedro Juan Núñez acometidos en España en las últimas décadas del pasado siglo, Luis Gil reivindica su figura al considerarlo «quizá el humanista valenciano de mayor envergadura y sin duda alguna el helenista español más importante del siglo XVI»(Gil Fernández, 2002: 142).

47 La comprendida entre el 7 de agosto y el 11 de diciembre de 1779 (Mayans, 2000: 228-278). 
cerciorado de que estos historiadores no aportaban variantes textuales. Por otro lado, el hecho de que lo tuvieran en cuenta demuestra su conocimiento del concepto de tradición indirecta.

Para la depuración de los errores acumulados en el texto, Mayans pensaba elegir entre las divergencias «las que sean mejores, que fácilmente se conocen por la perfección con que [P. J. Núñez] escribía» (2000: 255). Es decir, que su criterio para determinar qué podía considerarse genuino del autor era el viejo principio del usus scribendi. En 1757 había dicho los dos ejemplares del texto que manejaba estaban muy corruptos, «[...] I nadie puede restituirle como yo, que he leído mucho las obras deste insigne escritor» (Mayans, 1998: 97). Ahora decía a Cerdá: «Para nosotros es fácil» (Mayans, 2000: 229), «mas no es obra que pueda encomendarse a otros porque se ha de juzgar cómo se ha de leer» (2000: 259).

El olivense tampoco se olvida de mencionar la posibilidad de las variantes de autor, frecuentes en textos escolares como estas Explanationes, que podían dictarse en distintas ocasiones y lugares. Pone como ejemplo los dos títulos distintos que llevaban los manuscritos que cotejó, que perfectamente podían ser ambos originales de Núñez (2000: 259). Por otro lado, Mayans pone en alerta a Cerdá «de los errores de pluma del copiante, fáciles de observar» (2000: 263), que no debían atribuirse al autor.

Una vez seleccionadas razonadamente y apuntadas en un cuadernillo ${ }^{48}$ las lecturas preferidas, había que copiar la obra a mano una vez más (2000: 259). De este modo se obtendría un borrador listo para ser leído y corregido antes de llevarlo a la imprenta (2000: 229, 237, 240). Mayans no tenía en cuenta, o bien se le escapaba, que si llegaba a completarse la edición siguiendo estas directrices y la versión impresa se consagraba como textus receptus, no se estaría difundiendo un texto crítico, sino contaminado, que incorporaría lecturas de distintas tradiciones. Esto era habitual en ediciones humanísticas de los clásicos, por la imposibilidad de acceder a todos los manuscritos de una obra con los medios que aquellos editores tenían a su disposición. Sin embargo, hemos visto que el olivense había omitido deliberadamente el cotejo de testimonios que más o menos estaban a su alcance o al de Cerdá.

Pero dejemos que el propio Mayans nos describa su concepción de la constitutio textus de las Explanationes, una vez terminada la colación:

Quedó después por hacer la diligencia crítica de escoger la letura mejor, que para nosotros es fácil, i enmendado el libro, deve copiarse toda la obra antes de imprimirla, viendo en cada nombre de las poblaciones quál es su nombre, por si acaso está mal copiado. Por pedir esto uno o dos meses, no lo he egecutado [...] (2000: 229).

${ }^{48}$ La importancia de utilizar un nuevo cuadernillo para esto la explica Mayans así: «mi egemplar se confundiría si se le añadiessen correcciones» (Mayans, 2000: 263). 
De ese plazo estimado de entre uno y dos meses, acabaría pidiendo a Cerdá «un mes desocupado para copiar por sí las Prelecciones Geográphicas de Pedro Juan Núñez» (2000: 259). El alicantino lo convenció: «Para copiarle tengo un escriviente tan hábil que entiende mejor que yo mis borrones y qualquier cosa que se le presente, por mal escrita que esté, pues es copiante crítico, i (lo) hará a mi presencia» (2000: 261). Respecto a la emendatio de los topónimos, Mayans prescribía «consultar en Cellario ${ }^{49}$ i los Diccionarios Geográficos los nombres recientes de las poblaciones» (2000: 237). Cuando Cerdá le asegura haberse equipado para leer y corregir con «todos los geógraphos antiguos, Celario i lo demás necesario» (2000: 240), Gregorio sentencia: «Para copiarle bien corregido no se necesita sino de ser buen crítico como Vm., i saber bien latín, Cellario, Plinio, Estrabón i Mela, i buena ortografía» (2000: 242). A este respecto, conviene considerar que en 1759 Mayans había solicitado al editor ginebrino Gabriel Cramer la traducción latina de A. Polito del comentario griego del arzobispo Eustacio de Tesalónica (s. XII) a la obra de Dionisio Periegeta $^{50}$ (Mayans, 1993: 284). De esta obra dijo en 1766 que le sería útil para editar las Explanationes (Mayans, 1998: 340), y no cabe duda de ello, pues en su texto Pedro Juan Núñez cita a Eustacio repetidas veces.

Por otro lado, al hilo de los pasajes de cartas de Cicerón que Pedro Juan Núñez cita y traduce al castellano en las Explanationes, Mayans también trata de imponer a Cerdá su criterio:

Este insigne varón, como enseñaba a muchachos, quando cita a Cicerón solía añadir las traducciones valencianas de algunas cláusulas de Cicerón ${ }^{51}$, cosa que es útil para los niños, pero que desdice de la excelencia i gravedad de sus Comentarios. Estas traducciones, por no omitir cosa alguna suya, se podrán añadir al pie de cada página con sus llamadas (2000: 255).

49 «Cellario» es Christopher Keller o Christophorus Cellarius, autor de la Geographia antigua publicada en 1686, que apareció ampliada ya en 1692 con el título Geographia antiqua iuxta et nova, y se reimprimió en numerosas ocasiones a lo largo del s. XVIII.

${ }_{50}$ Eustacio de Tesalónica (1741). Eustathii Diaconi, a supplicibus libellis, et oratorum magistri, postea Archiepiscopi Thessalonicensis, Commentarii in Dionysium Periegetam, Alexandro Polito De Cler. Reg. Scholarum. Piarum, interprete. Coloniae Allobrogum (Ginebra): apud Haer. Cramer \& fratres Philibert.

51 Dar la traducción al vernáculo de citas de Cicerón no es infrecuente en las obras de Pedro Juan Núñez, de clara orientación didáctica, pues en el contexto del ciceronianismo humanista los términos y construcciones sintácticas que hubiese utilizado el Arpinate quedaban sancionados como modelos de la composición en neolatín. En el caso de las Explanationes, la autoridad de Cicerón se reivindica especialmente para los topónimos (sobre la tendencia ciceroniana de Pedro Juan Núñez: Núñez, 2014). El propio Mayans dice, cuando piensa en recoger este tipo de fórmulas de las obras de Núñez: «Será obra mui agradable para los que desean ser ciceronianos» (Mayans, 2000: 255). 
Gregorio mantendrá esta idea en cartas posteriores, «copiar a la margen la traducción de las frasecillas de Cicerón», puesto que merece la pena conservarla por ser de Núñez (2000: 263), o, mejor aún, omitir estas traducciones «notándolas con iniciales» y colocarlas «al pie de cada página» (2000: 277).

Otra de las preocupaciones de Mayans era la de que se incluyesen paratextos como el índice (2000: 263) y el prólogo (2000: 255)52. Asimismo, abogaba por incluir el mayor número de epígrafes para lograr una más cómoda y clara división del texto. Esta decisión lo lleva a aceptar los títulos de los capítulos de uno de los dos manuscritos que manejó, el de Del Olmo, muchos de los cuales no figuraban en el de Castelví (2000: 269).

Pero las adiciones más significativas que propuso Mayans, y que Cerdá parecía aceptar de buen grado, suponían acompañar las Explanationes de otros dos textos. Por un lado, quería incluir en el mismo tomo el otro escrito de tema geográfico de Núñez, la ya citada carta al jesuita A. Schott, sobre Pomponio Mela, que podía tomarse de su editio princeps en 1748 (2000: 243). El otro era menos acorde con el contenido de los Opuscula de Cerdá, que se reducían a obras de autores españoles: la versión latina de Prisciano del poema de Dionisio Periegeta, el mismo texto al que las Explanationes servían de scholia, del que Mayans había enviado al alicantino dos ediciones (2000: 275), especificándole: «El texto de Dionisio Afro deve ser como el impresso en Barcelona» (2000: 263), lo cual acataría Cerdá sin discusión, como demuestra en su respuesta a una carta de Mayans que no conservamos:

\begin{abstract}
Para que se conserve la edición original de Dionisio hecha por Núñez en Barcelona en 1572, voy copiando al margen de la de Vm. las notillas que de su mano havía puesto Núñez a la suya [...]. Y pues se ha tenido la fortuna de coger un egemplar, que sin duda sería el mismo que tendría Núñez para su uso, se pondrán como a Vm. le parece esas notillas al pie, y en lo demás se seguirá puntualmente todo lo demás que Vm. previene en su carta [...] (2000: 275).
\end{abstract}

52 En la correspondencia de Gregorio con Juan Bautista Hermán se testimonia que el olivense pensaba elaborar una biografía de Núñez para la edición de sus obras, como hizo para las del Brocense y Vives: «puede Vmd. ya pensar en escribir las vidas del Nebrissense i de Núñez para la colección de sus obras tantos años ha ideada» (Mayans, 2001: 267). Sobre la edición de las Explanationes, dijo a Cerdá: «Me contentaré con que se diga Ex Bibliotheca Mayansiana, i con que Vm. haga una Prefación digna de Vm. i de Núñez; i para hablar de sus obras embiaré a Vm. un apuntamiento de lo que he observado, i mi hermano añadirá lo que le parezca ser del caso» (Mayans, 2000: 255). Cerdá le aseguró: «Quedará un perpetuo monumento de lo que se debe a la Bibliotheca Maiansiana» (2000: 256), y ya le había dicho que en sus Opuscula figurarían semblanzas de los autores: «El Prólogo [...] es breve, porque las vidas de los autores no podrán serlo» (2000: 243). En una obra póstuma (la edición de Gil Polo, 1802) Cerdá anunciaba la publicación de las Explanationes en su colección de Opuscula, a partir de un manuscrito de Mayans (1882: 458), e incluía una biografía de Pedro Juan Núñez (1882: 284-287). 
Aunque no se conserva ningún ejemplar de esta edición de la Periegesis por Núñez, ni tenemos noticia alguna de ella, no hay razones para dudar de que existió ${ }^{53}$. No podemos creer con la misma seguridad que las anotaciones del ejemplar que manejaron Mayans y Cerdá eran autógrafas del humanista, pero, puesto que se ha perdido, este dato no tiene mayor relevancia a efectos prácticos que permitirnos conocer cómo operaban estos ilustrados ante lo que creían manuscrito por el propio Pedro Juan Núñez.

Recogemos, por último, un apunte de Cerdá sobre cómo proceder al imprimir una obra inédita, como las Explanationes (2000: 276), que fue favorablemente acogido por Mayans (2000: 277-278). Explica el alicantino que, para no manipular y posiblemente deteriorar la copia manuscrita que servía de modelo en la imprenta, cuando «es original, o antigua, o recomendable por algún título», encargaba y supervisaba una reproducción a mano, de manera que el primer ejemplar quedase al margen de este proceso y se conservase sin problemas. Concretamente, del códice que le envió Mayans dice que «no importaría nada que se destinase a la prensa», puesto que era «copia de copia y de un mal escribiente», pero que se lo restituiría de todas formas. El olivense, que con toda seguridad esperaba recuperar su manuscrito, vio con buenos ojos lo que Cerdá le decía. De hecho, en la misma carta le pedía que, para preservar su ejemplar de la traducción latina de Dionisio editada por Núñez, se utilizase como modelo en la imprenta el texto que él había publicado en su Tullius siguiendo el preparado por Núñez, que solo se emplearía después para cotejar las pruebas (2000: 278).

Visto el modus operandi de los dos ilustrados, no hace falta profundizar en la historia de la crítica textual ${ }^{54}$ para determinar que, si bien su trabajo no era en absoluto despreciable para la España de la época, quedaba ya muy rezagado respecto al de otras regiones de Europa. Mayans basaba la examinatio en cotejar las copias y realizar la selectio de las mejores lecturas según el principio del usus scribendi del autor, de su estilo. Por el dominio del latín que presuponía a Pedro Juan Núñez, cualquier lectura de calidad sospechosa ya era para él digna de eliminarse. Esta había sido la tendencia general de los humanistas del XVI, que para corregir un texto cotejaban los manuscritos que podían, pero daban más importancia a la calidad de las lecturas que al consensus codicum. Frente a esta precariedad de criterios, a través de la exégesis neotestamentaria de la primera mitad del s. XVIII ya se habían formulado principios como el de difficilior lectio potior de J. A. Bengel, o los de durior, rarior y brevior lectio potior de J. J. Wettstein. Mayans era ajeno a estos avances aun al final de su

${ }_{53}$ De hecho, hace muy probable esta hipótesis el hecho de que solo pueda confirmarse que Pedro Juan Núñez dictara las Explanationes durante su ejercicio de la cátedra de Retórica en Barcelona entre 1571 y 1573 (Pandiella, 2015).

${ }_{54}$ Para las referencias que damos a continuación remitimos a Morocho (2004: 63-89) especialmente, donde se recoge un artículo dedicado a la crítica textual de la Edad Moderna. 
vida, pero hay que tener en cuenta que se formó y desarrolló su actividad en España, un país en el que solo unos pocos representantes de la tradición humanística habían destacado en el ámbito de la crítica textual, en gran parte porque la presión inquisitorial no invitaba a hacerlo. En el presente caso, sin embargo, Gregorio Mayans llevó a cabo una búsqueda de ejemplares (recensio) de las De situ orbis explanationes in Dionysium Afrum de Núñez, se molestó en cotejarlos y, aunque no llegó a emprender la examinatio de las variantes, exigió a Cerdá un mes de dedicación para practicarla. Es cierto que las deficiencias de su collatio dejaban bastante que desear y que su examinatio se basaba en criterios nada científicos, pero esto no nos impide hacerlo merecedor de nuestra consideración.

\section{LAS EXPLANATIONES Y Francisco PÉREZ BAYER}

Hubo otro discípulo de Gregorio Mayans que también se fijó el objetivo de editar las Explanationes de Pedro Juan Núñez en la década de 1780. Se trata de Francisco Pérez Bayer (1711-1794), que entre otros campos humanísticos dedicó sus investigaciones al hebraísmo y al arabismo, y fue conocido como catedrático, canónigo e incluso preceptor de los infantes reales de Carlos III. Los hechos que vamos a resumir se datan en su etapa como bibliotecario mayor de la Real Librería, concretamente en 1784, y los conocemos a través de un puñado de cartas de las muchas que intercambió con Juan Antonio Mayans.

Pérez Bayer, a 9 de abril de 1784 (Mayans, 1977: 417-418), transmitió al Mayans menor su intención de editar para el siguiente septiembre la geografía de España del autor hispano-musulmán del s. XII Muhammad Al-Idrisi, conocido como El Nubiense, con texto árabe y su traducción latina. A esto pretendía poner «por apéndice» «las [notas] que hizo nuestro Pedro Juan Núñez a Dionysio Afro y la descripción que hizo de España y de las islas adiacentes», es decir, unos capítulos determinados de las Explanationes ${ }^{55}$. Por supuesto, todo ello lo acompañaría de sus propias notas. Habiendo asumido el cargo de bibliotecario mayor el año anterior, Bayer se sentía obligado a emprender trabajos para mayor prestigio de la institución que dirigía: en la misma carta habla de la necesidad de «que la biblioteca real dé alguna seña de vitalidad», pues «estaba y la hallé deplorable».

55 Pérez Bayer tenía también un alto concepto de Pedro Juan Núñez, como prueban estas palabras dirigidas a Gregorio Mayans tras recibir un ejemplar de la edición del Organum de Núñez por el olivense (Mayans, 1774): «yo he tenido siempre a Pedro Juan Núñez por el segundo Vives y en algunos puntos creo que le excede» (Mayans, 1977: 355). No obstante, parece que su deseo de editar las Explanationes no era premeditado, sino que nació a raíz de un manuscrito con este texto que «hallose casualmente en un alzado de la biblioteca real» (Mayans, 1977: 425); sobre este códice, veáse Pandiella (2015). 
En las epístolas posteriores el canónigo Mayans ${ }^{56}$ recomienda y envía a Pérez Bayer una traducción de otro texto geográfico árabe, el de Ismael Abulfeda, en el que el bibliotecario trabajaría para incluir lo relativo a España junto a los de Al-Idrisi y Núñez (1977: 418-420, 422-423). A continuación, Bayer confiesa su temor de ser incapaz de completar la empresa, a sabiendas de que el erudito maronita Miguel Casiri, español de origen libanés, y el benedictino Martín Sarmiento, la habían acometido anteriormente y abandonado por su dificultad (1977: 424-425). Además, en la misma carta dice: «El caso es que estoi ya comprometido con el conde de Floridablanca y en cierto modo con el público y ya es imposible retroceder». De nuevo Floridablanca sufragaba la edición.

En esta ocasión, los problemas que afectaban al editor no eran económicos, sino que se quejaba de la escasez de ediciones previas ${ }^{57}$ y de la dificultad para el correcto establecimiento de la toponimi ${ }^{58}$ (1977: 424-425, 428-429). No obstante, el bibliotecario valenciano sigue adelante, y a 19 de junio escribe a Juan Antonio a propósito del proyecto. Cuando menciona que se imprimirían los comentarios de Núñez a Dionisio, anuncia que la empresa se iba a retrasar por no estar aún fundidos los tipos árabes necesarios (1977: 430-434) ${ }^{59}$. Aunque mantenía su propósito de incluir aquella parte de las Explanationes en el mismo tomo, la improvisada adición de otro texto y el creciente volumen de anotaciones que iba confeccionando ya le habían hecho temer que todo ello sería «más material que para un tomo iustae molis» (1977: 429) ${ }^{60}$.

${ }^{56}$ En carta del 3 de julio de 1784, Juan Antonio Mayans informó de esta empresa de Bayer a Cerdá, que según hemos visto planeaba por entonces editar a Núñez: «El Ilmo. Bibliothecario quiere dar a luz la Geografía Arábigo-Española [...] i pensava añadirle la Descripción de España de Núñez sacada de los Comentarios a Dionisio» (Mayans, 2000: 348).

${ }^{57}$ Bayer había dado ya con todas las que había, solo dos (Mayans, 1977: 430): una con el texto árabe, salida de la imprenta de los Medici en Roma en 1592 como De Geographia Universali, y la famosa edición parisina de 1619 que fijó el título Geographia Nubiensis, una traducción latina abreviada a cargo de los sacerdotes maronitas Gabriel Sionita y Juan Hesronita, impresa por Jerome Blageart.

${ }^{58}$ Dice Bayer: «Acertar con los lugares todos que el Nubiense escribió, según a él le sonaban en su idioma o su peculiar ortografía y después los intérpretes maronitas desfiguraron enteramente en su versión latina, es assunto en mi juicio arduo y aún impossible, mientras no se hallen otros códices que lo aclaren» (Mayans, 1977: 425).

${ }_{59}$ Esta carta es el testimonio más amplio del trabajo de crítica de Bayer sobre el texto de El Nubiense. De ello diría Cerdá a J. A. Mayans: «El Sr. Bayer ha trabajado aquí unas notas mui atinadas sobre el Nubiense. Hará muchas emiendas a la traducción, i lo mismo con el Albulfeda que tenía aquí de Vm» (Mayans, 2000: 347).

${ }^{60}$ Lo mismo sugería Juan Antonio a Cerdá tratando el tema: «Al principio esta idea estava ceñida al Nubiense i pensava añadirle la Descripción de España de Núñez sacada de los Comentarios a Dionisio [...]. Al Nubiense acompañará la Descripción de España de 
Una vez más, la obra no llegó a imprimirse. No está claro el motivo que hizo abortar la empresa, si es que no se debió a que Pérez Bayer se viese superado por su dificultad. Desde luego, no pudo ser la falta de tipos árabes, puesto que en 1787 Antonio de Sancha imprimió el Diccionario español Latino-Arábigo de Francisco Cañes, en cuyo prólogo dice el autor: «Los caracteres, asi españoles como arabes, se han fundido en las matrices que S. M. tiene en la Biblioteca Real de Madrid» (Cañes, 1787: v).

Este resultado fue peor para Núñez que para El Nubiense, pues en el impulso de los estudios árabes y hebraicos de la época, otro erudito empleado en la Real Librería culminó una edición anotada bilingüe, en árabe y castellano, de la Descripción de España de Al-Idrisi: José Antonio Conde, que en 1799 la llevó a término en la Imprenta Real dirigida por Pedro Julián Pereira. Las De situ orbis explanationes in Dionysium Afrum de Pedro Juan Núñez, sin embargo, y a pesar de los tres intentos en una misma mitad de siglo que hemos historiado, permanecen inéditas.

\section{BIBLIOGRAFÍA CITADA}

Alarcos Martínez, Miguel (2015): «La Oratio habita a Petro Iohanne Nunnesio Valentino, in Academia Valentina, ad Philippum Tertium Margaritam Austriacam reges [...]: edición y traducción», Humanistica Lovaniensia. 64, pp. 259-281.

Alemany Peiró, Amparo (1994). Juan Antonio Mayans y Siscar (1718-1801). Esplendor y crisis de la Ilustración valenciana. Valencia: Ayuntamiento de Oliva.

Antonio, Nicolás (1788). Bibliotheca Hispana Nova, sive Hispanorum scriptorum qui ab anno MD ad MDCLXXXIV floruere notitia. Madrid: J. de Ibarra, 2 vols. 1. ${ }^{a}$ ed. Roma, 1672.

Barbeito Díez, Pilar (2000a). «Impresos de Pedro Juan Núñez: estudio bibliográfico», Cuadernos de Filología Clásica. Estudios latinos. 18, pp. 335-386.

Barbeito Díez, Pilar (2000b). Pedro Juan Núñez, humanista valenciano. Valencia: Biblioteca Valenciana.

Bragado Lorenzo, J., y C. Caro López (2004). «La censura gubernativa en el siglo XVIII», Hispania. 217, pp. 571-600.

Cañes, Francisco (1787). Diccionario español latino-arábigo en que siguiendo el diccionario abreviado de la Academia se ponen las correspondencias latinas y arábes, para facilitar el estudio de la lengua arábiga á los misioneros, y á los que viajaren ó contratan en Africa y Levante. Madrid: A. de Sancha.

Cerdá Rico, F. (ed.) (1781). Clarorum Hispanorum Opuscula selecta et rariora tum Latina tum Hispana, I. Madrid: A. de Sancha.

Fuente Cornejo, Toribio (2012). «Contribución a la historia de los Miscellanea Philologica de Pedro Juan Núñez», Anals de la Real Academia de Cultura Valenciana. 87, pp. 9-22

\footnotetext{
Albulfeda $[\mathrm{sic}]$, i la mies se ha hecho tan copiosa con las notas atinadas que se añade, que solamente lo arábigo podrá formar un volumen regular» (Mayans, 2000: 348).
} 
Fuster, Justo Pastor (1827-1830). Biblioteca Valenciana de los Escritores que florecieron hasta nuestros días. Valencia: J. Ximeno, 2 vols.

García Cuadrado, Amparo (2001). «Un proceso de impresión. La Censura de historias fabulosas de Nicolás Antonio», Boletín de la Asociación Andaluza de Bibliotecarios. 16, 64, pp. 89-122.

García Ejarque, Luis (1997). La Real Biblioteca de S. M. y su personal (1712-1836). Madrid: Tabapress.

Gil Fernández, Luis (1976). Campomanes, un helenista en el poder. Madrid: Fund. Univ. Esp.

Gil Fernández, Luis (2002). «El humanismo valenciano del siglo XVI», en José María Maestre Maestre, Luis Charlo Brea y Joaquín Pascual Barea (coord.), Humanismo y pervivencia del mundo clásico: homenaje al profesor Antonio Fontán. Alcañiz-Madrid: Ediciones del Laberinto, vol. I, pp. 57-160.

Gil Polo, Gaspar (1802). La Diana enamorada: cinco libros que prosiguen los VII de Jorge de Montemayor. Madrid: A. de Sancha.

Grau Codina, Ferrán (1994). Las Retóricas de Pedro Juan Núñez (ediciones y manuscritos) [Tesis doctoral inédita]. Valencia: Universidad, $<$ http://roderic.uv.es/handle/10550/38848>.

Hoyos Ruiz, Antonio (1955-1956). «Notas a la vida y obra de D. Gregorio Mayans y Siscar», Anales de la Universidad de Murcia. 3-4, pp. 233-278.

Martínez Moraga, Consuelo (2004). La Rhetórica ilustrada de Mayans y Siscar. Valencia: Publicaciones del Ayuntamiento de Oliva.

Mayans y Siscar, Gregorio ${ }^{61}$ (1753). Specimen bibliothecae Hispano-Maiansianae sive Idea novi catalogi critici opervm scriptorum Hispanorum, quae habet in sva bibliotheca Gregorivs Maiansivs generosus Valentinvs ex Museo Davidis Clementis. Hannover: J. W. Schmid.

Mayans y Siscar, Gregorio (ed.) (1767). Clarorum Valentinorum Orationes Selectae. Lausana: F. Grasset.

Mayans y Siscar, Gregorio (ed.) (1768). Tullius sive De conjugenda Latinitate cum doctrina et eloquentia libri quadraginta. Valencia: F. Burguete.

Mayans y Siscar, Gregorio (ed.) (1774). Organum rhetoricum et oratorium concinnatum ex arte rhetorica Aelii Antonii Nebrissensis, cum notis Gregorii Majansii, et ex institutionibus oratoris Petri Io. Nunnesii Valentini, cum ipsius annotationibus manuscriptis. Valencia: F. Burguete.

Mayans y Siscar, Gregorio (1972). Epistolario II. Mayans y Burriel. Transcripción, notas y estudio preliminar de Antonio Mestre. Valencia: Ayuntamiento de Oliva.

Mayans y Siscar, Gregorio (1975). Epistolario IV. Mayans y Nebot (1735-42), un jurista teórico y un práctico. Transcripción, notas y estudio preliminar de Mariano Peset. Valencia: Ayuntamiento de Oliva.

Mayans y Siscar, Gregorio (1977). Epistolario VI. Mayans y Pérez Bayer. Transcripción, notas y estudio preliminar de Antonio Mestre. Valencia: Ayuntamiento de Oliva.

Mayans y Siscar, Gregorio (1983). Obras completas. Vol. I, Historia. Edición preparada por Antonio Mestre. Valencia: Ayuntamiento de Oliva.

Mayans y Siscar, Gregorio (1984). Obras completas. Vol. II, Literatura. Edición preparada por Antonio Mestre. Valencia: Ayuntamiento de Oliva.

${ }^{61}$ Buena parte de la obra editada de Gregorio Mayans puede consultarse en la Biblioteca Valenciana Digital, <http://bivaldi.gva.es/estaticos/contenido.cmd?pagina=estaticos/ mayans/mayans_indice_general> [ref. de 20/06/2017]. 
Mayans y Siscar, Gregorio (1986). Obras completas. Vol. V, Ensayos y Varia. Edición preparada por Antonio Mestre. Valencia: Ayuntamiento de Oliva.

Mayans y Siscar, Gregorio (1989). Epistolario IX. Mayans y Martínez Pingarrón, 3: Real Biblioteca y política cultural. Transcripción, notas y estudio preliminar de Antonio Mestre. Valencia: Ayuntamiento de Oliva.

Mayans y Siscar, Gregorio (1990). Epistolario X. Mayans con Manuel Roda y Conde de Aranda. Transcripción, notas y estudio preliminar de Antonio Mestre. Valencia: Ayuntamiento de Oliva.

Mayans y Siscar, Gregorio (1993). Epistolario XII. Mayans y los libreros. Transcripción y estudio preliminar de Antonio Mestre. Valencia: Ayuntamiento de Oliva.

Mayans y Siscar, Gregorio (1996). Epistolario XIV. Mayans y los altos cuadros de la Magistratura y Administración borbónica, 1 (1716-1750). Transcripción, notas y estudio preliminar de Antonio Mestre Sanchis y Pablo Pérez García. Valencia: Ayuntamiento de Oliva.

Mayans y Siscar, Gregorio (1997). Epistolario XV. Mayans y los altos cuadros de la Magistratura y Administración borbónica, 1 (1716-1750). Transcripción, notas y estudio preliminar de Antonio Mestre Sanchis y Pablo Pérez García. Valencia: Ayuntamiento de Oliva.

Mayans y Siscar, Gregorio (1998). Epistolario XVI. Mayans y los altos cuadros de la Magistratura y Administración borbónica, 3. Fernando José de Velasco y Ceballos (17531781). Estudio preliminar, transcripción y notas por Antonio Mestre Sanchis y Pablo Pérez García. Valencia: Ayuntamiento de Oliva.

Mayans y Siscar, Gregorio (2000). Epistolario XVII. Cartas literarias. Correspondencia de los hermanos Mayans con los hermanos Andrés, F. Cerdá y Rico, Juan Bautista Muñoz y José Vega Sentmenat. Estudio preliminar, transcripción y notas por Amparo Alemany Peiró. Valencia: Ayuntamiento de Oliva.

Mayans y Siscar, Gregorio (2001). Epistolario XVIII. Correspondencia de los hermanos Mayans con el canónigo Juan Bautista Hernán, 1. Estudio preliminar, transcripción y notas por Vicente León Navarro, con la colaboración de Erena León La Parra. Valencia: Ayuntamiento de Oliva.

Mayans y Siscar, Gregorio (2005). Epistolario XX. Los hermanos Mayans y los inquisidores, 1. La «clientela» del inquisidor Andrés Orbe. Estudio preliminar, transcripción y notas por Amparo Alemany Peiró. Valencia: Publicaciones del Ayuntamiento de Oliva.

Mayans y Siscar, Gregorio (2006). Epistolario XXI. Mayans y los austracistas. Estudio preliminar, transcripción y notas de Antonio Mestre Sanchis. Valencia: Ayuntamiento de Oliva.

Mayans y Siscar, Gregorio (2007). Epistolario XXII. Los hermanos Mayans y los inquisidores, 2. Estudio preliminar, transcripción y notas por Amparo Alemany Peiró. Valencia: Ayuntamiento de Oliva.

Mayans y Siscar, Juan Antonio (1771). Ilici, hoi la villa de Elche, ilustrada con varios discursos. Valencia, F. Burguete.

Mela, P. (1748). Pomponii Melae De situ orbis libri III: cum notis integris Hermolai Barbari, Petri Joannis Olivarii, Fredenandi Nonii Pintiani, Petri Ciacconii, Andreae Schotti, Isaaci Vossii et Jacobi Gronovii. Accedunt Petri Joannis Nunnesii Epistola de patriaPomponii Melae [et] adnotata in proemium atque duo priora capita Libri I et Jacobi Perizonii adnotata ad Libri I capita septemdecim. Curante Abrahamo Gronovio. Leiden: S. Luchtmans.

Mestre Sanchis, Antonio (1970). Historia, fueros y actitudes políticas: Mayans y la historiografia del siglo XVIII. Valencia: Ayuntamiento de Oliva. 
Mestre Sanchis, Antonio (2000). «Humanismo e ilustración: Cerdá Rico», Bulletin Hispanique. 102, 2, pp. 453-471. doi: 10.3406/hispa.2000.5052.

Mestre Sanchis, Antonio (2003). Mayans: proyectos y frustraciones. Valencia: Ayuntamiento de Oliva.

Morocho Gayo, Gaspar (2004). Estudios de crítica textual. Murcia: Universidad de Murcia.

Novísima Recopilación de las leyes de España dividida en XII libros. En que se reforma la Recopilación publicada por el Señor Don Felipe II en el año de 1567, reimpresa últimamente en el de 1775: Y se incorporan las pragmáticas, cédulas, decretos, órdenes y resoluciones Reales, y otras providencias no recopiladas y expedidas hasta el de 1804 (Con tres índices generales) [...] mandada formar por Carlos IV (1805). Madrid: [s. n.], 5 vols.

Núñez González, Juan María (2011). «Notas bibliográficas sobre Pedro Juan Núñez, humanista valenciano», Liburna. 4, pp. 257-263.

Núñez González, Juan María (2014). «Pedro Juan Núñez y el ciceronianismo», Anals de la Real Acadèmia de Cultura Valenciana. 89, pp. 63-86.

Olmo, José Vicente del (1681). Nueva descripción del orbe de la tierra. Valencia: J. L. Cabrera.

Pandiella Gutiérrez, Paulino (2015). «Los códices de las De situ orbis explanationes in Dionysium Afrum de Pedro Juan Núñez», Lope de Barrientos. Seminario de Cultura. 6, pp. 125-141.

Pérez i Durá, F. Jordi (2010). «La biblioteca de un ilustrado, portavoz de la cultura española en Europa: el Specimen de Gregorio Mayans», en José María Maestre Maestre, Joaquín Pascual Barea y Luis Charlo Brea (ed.), Humanismo y pervivencia del mundo clásico. Homenaje al profesor Antonio Prieto. Alcañiz - Madrid: IEH - CSIC, pp. 2481-2500

Peset Llorca, Vicente (1975). Gregori Mayans i la cultura de la Il.lustració, amb un pròleg d'Antoni Mestre. Barcelona: Curial.

Peset, Mariano y José Luis Peset (1975). Gregorio Mayans y la reforma universitaria. Idea del nuevo método que se puede practicar en la enseñanza de las Universidades de España. Valencia: Ayuntamiento de Oliva.

Rausell Guillot, Helena (2002). «Los erasmistas valencianos en la obra de los ilustrados», Estudis: Revista de historia moderna. 28, pp. 255-272.

Villanueva, Jaime (1803-1852). Viage literario a las Iglesias de España. Madrid: Imprenta Real, 22 vols.

Ximeno, Vicente (1747-1749). Escritores del Reyno de Valencia, chronologicamente ordenados desde el año MCCXXXVIII hasta el de MDCC. Valencia: J. E. Dolz, 2 vols. 